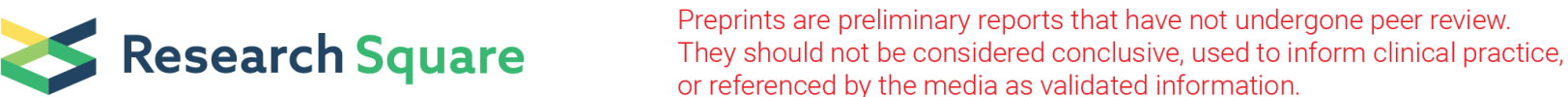

\section{Study On Laying Performances, Blood Biochemical Indicators, Feather Condition And Antibody Titers of Layer Breeders Among Different Tiers In Mating Cages During The Peak Laying Period*}

\section{Yan LI}

Institute of Animal Husbandry and Veterinary Medicine

\section{Rui-yu MA}

Institute of Animal Husbandry and Veterinary Medicine

Yi WAN

Institute of Animal Husbandry and Veterinary Medicine

Renrong QI

Institute of Animal Husbandry and Veterinary Medicine

Jun-ying LI

Institute of Animal Husbandry and Veterinary Medicine

Wei LIU

Institute of Animal Husbandry and Veterinary Medicine

Hai-jun CUI

Jiangxi Huayu Poultry Breeding Co., Ltd

Xin ZHANG

Jiangxi Huayu Poultry Breeding Co., Ltd

Zhejie LIU

Jiangxi Huayu Poultry Breeding Co., Ltd

Kai ZHAN ( $\nabla$ zhankai633@126.com )

Institute of Animal Husbandry and Veterinary Medicine

\section{Research Article}

Keywords: cage tier, mating cage, peak laying period, laying performance, blood biochemical indicator, feather condition, antibody titer

Posted Date: September 15th, 2021

DOl: https://doi.org/10.21203/rs.3.rs-804176/v1 
License: (c) (i) This work is licensed under a Creative Commons Attribution 4.0 International License. Read Full License 


\section{Abstract}

The present study was conducted to determine the effect of cage tier on laying performances, blood biochemical indicators, feather condition and antibody titers of layer breeders among different tiers in mating cages during the peak laying period. All birds (Hy-Line Brown parent stock breeders) at 27 weeks of age were housed in 4-tier mating cage. Laying performances, egg quality characteristics, blood biochemical indicators, antibody titers and feather condition were measured. The highest laying rate was recorded at $2^{\text {nd }}$ tier, followed by $4^{\text {th }}$ tier and $3^{\text {rd }}$ tier, and the lowest at $1^{\text {st }}$ tier. There were no significant differences among different tiers in terms of percentage of defective eggs and hatchability performances. Yolk color was significantly lower at $2^{\text {nd }}$ tier than at other tiers. However, no distinct differences in egg weight, shell weight, shell color, shell breaking strength, egg shape index, yolk weight, albumen height, haugh units were observed. Concentrations of serum CK, T-AOC, SOD, GPx and MDA, and the antibody titers did not change substantially among different tiers. Moreover, the average feather score for each individual part of the body and an overall average score for birds were not significantly different. We confidently conclude that cage tier may be a contributing factor for layer performances. These findings will be helpful for application of natural mating system in layer industry.

\section{Introduction}

Poultry welfare is an important topic all over the world, there is an increasing focus on poultry welfare. Natural mating of poultry is that male and female animals are raised together and naturally mated by virtue of their sexual instinct. Natural mating has been gradually popularized and applied in China for some special advantages, such as improvement of animal welfare, efficient use of land, remarkable reduction in labor cost and etc. (Li et al. 2018; Bilcik 2005; Brillard et al. 2004). However, this field is still in its infancy, with great work on collection and analysis of the preliminary data, especially that limited information is available on cage tier.

Increasing evidence suggests that cage tier is one of the most important factor in poultry production as microenvironmental conditions are not the same in every part of the cage tier, and unavoidable variation in environments might occur among different tiers in multitier cage systems. There are several studies relating the effects of cage tier on poultry performances. Jackson (1987) reported that performance as measured by egg production, egg weight, and mortality significantly deteriorated in a linear fashion progressing from the bottom to the top in three and four tier cages. Yildiz et al. (2006) confirmed that egg production for hens at the top tier was greater than for hens at the middle and bottom tiers. Karaman et al. (2013) found that mortality was significantly higher in the third tier than in other tiers, and effects of cage tier on egg blood stains were found to be significant. Moreover, investigations were also conducted in hen day production and feed consumption (Grover et al. 1972), egg weight (Hurnik et al. 1974), egg production (Sefton 1976) and tonic immobility (Şekeroğlu et al. 2014). All of these evidences suggest that cage tier plays a key role in affecting poultry performances. However, these studies are still quite limited; in particular, there is a lack of such knowledge in the mating cage system. Therefore, a systematic investigation of cage tier is required. 
The present study was conducted to determine the effect of cage tier on laying performances, blood biochemical indicators, feather condition and antibody titers of layer breeders among different tiers in mating cages during the peak laying period.

\section{Materials And Methods}

\section{Birds and experimental design}

Birds (Hy-Line Brown parent stock breeders) were obtained at 27 weeks of age from Jiangxi Huayu Poultry Breeding Co., Ltd (Yichun, Jiangxi Province). They were placed into 4-tier mating cage (Hytem Equipment Manufacturing(Tianjin) Co., Ltd., Tianjin), and were subjected to a photoperiod of $17 \mathrm{~h}$ light and $7 \mathrm{~h}$ dark/d. All experimental birds were divided into four groups on the basis of tier with 5 cages (480 $\mathrm{cm}$ length $\times 120 \mathrm{~cm}$ width $\times 80 \mathrm{~cm}$ height) and each cage contained 10 roosters and 90 laying hens. Performance parameters, including laying performances, egg quality characteristics, blood biochemical indicators, antibody titers and feather condition were recorded daily. The entire experiment lasted for one month. Feed and water were given ad libitum throughout the experimental period. and the ingredients and nutrient concentration of basal diet are shown in Table 1.

Table 1

Ingredients and nutrient concentration of basal diet

\begin{tabular}{|llll|}
\hline Ingredients & Nutrient concentration & Ingredients & Nutrient concentration \\
\hline Metabolizable energy (MJ/kg) & 12.14 & Arginine (\%) & 0.89 \\
\hline Crude protein (\%) & 17.48 & Valine (\%) & 0.77 \\
\hline Lysine (\%) & 0.87 & Linoleic acid (\%) & 0.97 \\
\hline Methionine (\%) & 0.43 & Calcium (\%) & 3.98 \\
\hline Methionine + cystine (\%) & 0.71 & Phosphorus (\%) & 0.45 \\
\hline Isoleucine (\%) & 0.67 & Sodium (\%) & 0.17 \\
\hline Threonine (\%) & 0.66 & Chloride (\%) & 0.17 \\
\hline Tryptophan (\%) & 0.20 & & \\
\hline
\end{tabular}

\section{Measurements of mortality and laying performances}

hen-day egg production, defective eggs and the number of dead birds were recorded daily and laying rate, percentage of defective eggs and mortality were calculated by recorded data. Moreover, eggs were collected and hatched in a commercial layer hatcheries in two consecutive weeks. On the 5th day of incubation, unfertilized eggs were recorded and eliminated. On the 18th day of incubation, eggs with dead embryos also were recorded and eliminated. Finally, reproductive performances were evaluated including 
fertility, rate of water loss, male-to-female ratio, hatchability of setting eggs, percentage of healthy chicks and average pullet hatching weight etc..

\section{Egg quality analysis}

Thirty eggs from each tier were randomly collected and used to determine the egg quality. Egg weight, albumen height, yolk color and Haugh units were measured using automatic egg multitester equipment (EMT-5200, Robotmation Co., Ltd., Tokyo, Japan). Shell color was recorded with a reflectometer (PRSEvans Electroselenium Ltd, Halstead, Essex) as an average of three measurements taken at the equatorial region, blunt region and sharp region of the egg Shell weight using a portable electronic balance. Length and width of each egg were gauged with for egg shape index calculation (egg width /egg length $\times 100$ ). Shell breaking strength was determined using an shell strength device (EGG-0503, Robotmation CO., Ltd, Tokyo, Japan) and shell thickness (without the inner and outer shell membranes) using a shell thickness meter (ESTG-1, ORKA Food Technology Co., Ltd. Ramat Hasharon, Israel).

\section{Determination of blood biochemical parameters}

Blood samples ( $3 \mathrm{ml} / \mathrm{bird}$ ) were collected from 10 roosters and 10 laying hens per group by puncturing the brachial vein using a sterilized syringe. After centrifugation at $3000 \mathrm{rpm}$ for 10 minutes at room temperature, the separated serum was delivered to Adicon Clinical Laboratories (ADICON Clinical Laboratory Inc., Hefei, China) for determination of creatine kinase (CK), total antioxidant capacity (T-AOC), superoxide dismutase (SOD), glutathione peroxidase (GPX) and malondialdehyde (MDA) by an automatic clinical chemistry analyzer.

\section{Determination of antibody titer}

Blood samples ( $3 \mathrm{ml} / \mathrm{bird}$ ) were collected from 10 roosters and 10 laying hens per group and serum was separated by centrifugation at $3000 \mathrm{rpm} / \mathrm{min}$ for 10 minutes. The antibody titers against H5N6, H5N7, H5N7 and H5N9 subtypes avian influenza virus (AIV) and newcastle disease virus (NDV) were measured by $\mathrm{HI}$ test. The referral antigens and their corresponding positive sera used in this study were supplied by the Harbin Veterinary Research Institute, China.

\section{Feather condition}

Thirty birds (15 male and 15 female) per group were chosen at random and individually scored on five parts of the body (neck, breast, back, wings and tail) using established 4-point scale (Tauson, 1986). A higher score represented a better feather condition. Finally, the sum of these five parts was also used for analyses.

\section{Statistical analysis}

Data presented as means $( \pm \mathrm{SE})$ was analyzed using ANOVA followed by the Tukey's post hoc test, using Origin Pro 8.0 software (OriginLab Corporation, Northampton, USA). A value of $p<0.05$ was considered statistically significant. 


\section{Results}

\section{Laying performances and mortality}

Laying performances and mortality in all four groups were demonstrated in Table 2. No dead birds were found during the experiment. The highest laying rate was recorded at 2 nd tier, followed by 4 th tier and 3 rd tier, and the lowest at 1st tier. Moreover, no differences in percentage of defective eggs were observed in the studied groups $(P>0.05)$. Hatching experiments displayed that there were no significant differences among different tiers in terms of fertility, rate of water loss, male-to-female ratio, hatchability of setting eggs, percentage of healthy chicks and average pullet hatching weight $(P>0.05)$.

Table 2

mortality and laying performances of layer breeders among different tiers in the mating cage

\begin{tabular}{|c|c|c|c|c|c|}
\hline \multirow[t]{2}{*}{ Parameters } & \multicolumn{5}{|l|}{ Cage tier } \\
\hline & \multirow[t]{2}{*}{ 1st tier } & \multicolumn{2}{|c|}{ 2nd tier } & \multicolumn{2}{|c|}{ 4th tier } \\
\hline \multicolumn{5}{|l|}{ Mortality } & \\
\hline Hens & & $0.00 \pm 0.00$ & $0.00 \pm 0.00$ & $0.00 \pm 0.00$ & $0.00 \pm 0.00$ \\
\hline Roos & & $0.00 \pm 0.00$ & $0.00 \pm 0.00$ & $0.00 \pm 0.00$ & $0.00 \pm 0.00$ \\
\hline \multicolumn{6}{|c|}{ Laying performance } \\
\hline \multicolumn{2}{|c|}{ Laying rate (\%) } & $\begin{array}{l}91.14 \pm \\
0.86^{\mathrm{a}}\end{array}$ & $97.01 \pm 0.50^{c}$ & $\begin{array}{l}93.26 \pm \\
0.57^{\mathrm{ab}}\end{array}$ & $\begin{array}{l}94.64 \pm \\
0.64^{b c}\end{array}$ \\
\hline \multicolumn{2}{|c|}{$\begin{array}{l}\text { Percentage of defective eggs } \\
(\%)\end{array}$} & $0.27 \pm 0.06$ & $0.13 \pm 0.04$ & $0.19 \pm 0.04$ & $0.22 \pm 0.06$ \\
\hline \multicolumn{2}{|c|}{ Fertility (\%) } & $96.23 \pm 0.52$ & $96.43 \pm 0.00$ & $97.02 \pm 0.34$ & $\begin{array}{l}95.63 \pm \\
1.21\end{array}$ \\
\hline \multicolumn{2}{|c|}{ Rate of water loss (\%) } & $12.63 \pm 0.19$ & $12.70 \pm 0.23$ & $12.11 \pm 0.10$ & $\begin{array}{l}12.64 \pm \\
0.49\end{array}$ \\
\hline \multicolumn{2}{|c|}{ Male-to-female ratio } & $1.08 \pm 0.15$ & $1.08 \pm 0.04$ & $1.01 \pm 0.04$ & $1.08 \pm 0.19$ \\
\hline \multicolumn{2}{|c|}{$\begin{array}{l}\text { Hatchability of setting eggs } \\
(\%)\end{array}$} & $87.70 \pm 0.20$ & $88.30 \pm 1.21$ & $89.29 \pm 0.34$ & $\begin{array}{l}90.28 \pm \\
1.39\end{array}$ \\
\hline \multicolumn{2}{|c|}{$\begin{array}{l}\text { Percentage of healthy chicks } \\
(\%)\end{array}$} & $47.51 \pm 3.93$ & $47.86 \pm 1.12$ & $47.78 \pm 0.77$ & $\begin{array}{l}47.17 \pm \\
4.64\end{array}$ \\
\hline \multicolumn{2}{|c|}{$\begin{array}{l}\text { Average pullet hatching } \\
\text { weight }(\mathrm{g})\end{array}$} & $40.63 \pm 0.24$ & $40.72 \pm 0.32$ & $40.86 \pm 0.31$ & $\begin{array}{l}41.01 \pm \\
0.22\end{array}$ \\
\hline
\end{tabular}

\section{Egg quality}

Table 3 summarized the effects of cage tier on egg quality characteristics (Table 3). Obviously, yolk color was significantly lower at 2 nd tier than at other tiers $(P<0.05)$. However, no distinct differences in egg 
weight, shell weight, shell color, shell breaking strength, egg shape index, yolk weight, albumen height, haugh units were observed in the studied groups $(P>0.05)$.

Table 3

egg quality characteristics of layer breeders among different tiers in the mating cage

\begin{tabular}{|lllll|}
\hline Egg quality characteristics & \multicolumn{3}{l}{ Cage tier } & \\
\cline { 2 - 5 } & 1st tier & 2nd tier & 3rd tier & 4th tier \\
\hline Egg weight $(\mathrm{g})$ & $60.70 \pm 0.78$ & $59.86 \pm 0.66$ & $61.06 \pm 1.04$ & $62.49 \pm 1.01$ \\
\hline Shell weight $(\mathrm{g})$ & $8.14 \pm 0.17$ & $8.07 \pm 0.10$ & $8.00 \pm 0.10$ & $8.22 \pm 0.11$ \\
\hline Shell color & $24.96 \pm 0.75$ & $23.99 \pm 0.63$ & $24.38 \pm 0.85$ & $24.26 \pm 0.59$ \\
\hline shell breaking strength $\left(\mathrm{kg} / \mathrm{cm}^{2}\right)$ & $4.32 \pm 0.15$ & $4.39 \pm 0.12$ & $4.46 \pm 0.12$ & $4.41 \pm 0.12$ \\
\hline Egg shape index & $1.30 \pm 0.01$ & $1.28 \pm 0.01$ & $1.27 \pm 0.01$ & $1.31 \pm 0.01$ \\
\hline Yolk weight $(\mathrm{g})$ & $16.61 \pm 0.21$ & $16.43 \pm 0.22$ & $16.67 \pm 0.27$ & $16.59 \pm 0.22$ \\
\hline Yolk color & $9.49 \pm 0.06^{\mathrm{a}}$ & $8.35 \pm 0.12^{\mathrm{b}}$ & $9.60 \pm 0.07^{\mathrm{a}}$ & $9.71 \pm 0.05^{\mathrm{a}}$ \\
\hline Albumen height $(\mathrm{mm})$ & $6.13 \pm 0.21$ & $6.29 \pm 0.24$ & $6.34 \pm 0.37$ & $6.09 \pm 0.29$ \\
\hline Haugh units & $76.89 \pm 1.62$ & $78.09 \pm 1.84$ & $77.88 \pm 2.53$ & $75.94 \pm 2.18$ \\
\hline
\end{tabular}

\section{Blood biochemical indicators}

Results of blood biochemical indicators were displayed in Table 4. Concentrations of serum CK, T-AOC, SOD, GPx and MDA for hens showed no substantial differences among different tiers $(P>0.05)$. Quite coincidentally, a similar phenomenon was observed for roosters. 
Table 4

Results of blood biochemical indicators of layer breeders among different tiers in the mating cage

\begin{tabular}{|cllll|}
\hline Parameters & \multicolumn{2}{l}{ Cage tier } & & \\
\cline { 2 - 5 } & 1st tier & 2nd tier & 3rd tier & 4th tier \\
\hline Hen & & & & \\
\hline CK $(\mathrm{U} / \mathrm{L})$ & $241.78 \pm 8.01$ & $240.02 \pm 5.53$ & $241.15 \pm 9.60$ & $220.75 \pm 8.61$ \\
\hline T-AOC $(\mathrm{U} / \mathrm{mL})$ & $99.75 \pm 7.01$ & $96.63 \pm 4.30$ & $76.94 \pm 8.12$ & $88.31 \pm 8.01$ \\
\hline SOD $(\mathrm{U} / \mathrm{ml})$ & $156.90 \pm 5.11$ & $158.38 \pm 3.06$ & $148.37 \pm 7.57$ & $153.38 \pm 4.68$ \\
\hline GPx $(\mathrm{mlU} / \mathrm{ml})$ & $30.43 \pm 1.84$ & $30.39 \pm 1.44$ & $25.79 \pm 3.01$ & $28.74 \pm 2.05$ \\
\hline MDA $(\mathrm{nmol} / \mathrm{ml})$ & $14.56 \pm 1.24$ & $13.70 \pm 1.12$ & $16.61 \pm 2.82$ & $15.55 \pm 1.51$ \\
\hline Rooster & & & & \\
\hline CK $(\mathrm{U} / \mathrm{L})$ & $241.72 \pm 3.30$ & $237.99 \pm 8.16$ & $234.12 \pm 8.02$ & $236.68 \pm 4.32$ \\
\hline T-AOC $(\mathrm{U} / \mathrm{mL})$ & $99.07 \pm 5.61$ & $89.08 \pm 9.53$ & $99.91 \pm 4.55$ & $91.28 \pm 6.47$ \\
\hline SOD $(\mathrm{U} / \mathrm{ml})$ & $166.39 \pm 2.53$ & $161.68 \pm 7.59$ & $170.13 \pm 3.90$ & $156.11 \pm 4.90$ \\
\hline GPx $(\mathrm{mlU} / \mathrm{ml})$ & $32.42 \pm 1.88$ & $28.64 \pm 2.48$ & $32.11 \pm 1.13$ & $28.57 \pm 1.53$ \\
\hline MDA $(\mathrm{nmol} / \mathrm{ml})$ & $16.71 \pm 1.65$ & $14.49 \pm 1.31$ & $13.24 \pm 0.86$ & $14.52 \pm 1.41$ \\
\hline
\end{tabular}

\section{Antibody titer}

As illustrated in Table 6, the antibody titers of all samples did not change substantially among different tiers $(P>0.05)$. Further analysis found that each antibody titer in the blood of hens were higher than 6 . Likewise, roosters exhibited similar antibody response. 
Table 6

results of antibody titer of layer breeders among different tiers in the mating cage $\left(\log _{2}\right)$

\begin{tabular}{|c|c|c|c|c|}
\hline \multirow[t]{2}{*}{ Parameters } & \multicolumn{4}{|l|}{ Cage tier } \\
\hline & 1st tier & 2nd tier & 3rd tier & 4th tier \\
\hline \multicolumn{5}{|l|}{ Hen } \\
\hline H5N6 & $8.00 \pm 0.30$ & $7.64 \pm 0.25$ & $8.08 \pm 0.37$ & $8.13 \pm 0.19$ \\
\hline H5N7 & $6.73 \pm 0.27$ & $6.64 \pm 0.20$ & $6.77 \pm 0.20$ & $7.20 \pm 0.17$ \\
\hline H5N7 & $7.00 \pm 0.36$ & $6.50 \pm 0.31$ & $7.08 \pm 0.29$ & $7.47 \pm 0.17$ \\
\hline H5N9 & $11.18 \pm 0.26$ & $11.29 \pm 0.24$ & $11.23 \pm 0.30$ & $10.87 \pm 0.17$ \\
\hline NDV & $10.36 \pm 0.24$ & $10.14 \pm 0.23$ & $9.92 \pm 0.37$ & $10.20 \pm 0.20$ \\
\hline \multicolumn{5}{|l|}{ Rooster } \\
\hline H5N6 & $8.60 \pm 0.43$ & $8.20 \pm 0.42$ & $9.40 \pm 0.21$ & $9.31 \pm 0.25$ \\
\hline H5N7 & $7.20 \pm 0.28$ & $7.33 \pm 0.30$ & $7.73 \pm 0.25$ & $7.94 \pm 0.21$ \\
\hline H5N7 & $7.93 \pm 0.42$ & $7.67 \pm 0.39$ & $8.33 \pm 0.25$ & $8.25 \pm 0.21$ \\
\hline H5N9 & $12.33 \pm 0.23$ & $12.13 \pm 0.22$ & $12.00 \pm 0.22$ & $12.38 \pm 0.15$ \\
\hline NDV & $11.07 \pm 0.25$ & $11.00 \pm 0.22$ & $11.27 \pm 0.23$ & $11.00 \pm 0.20$ \\
\hline
\end{tabular}

\section{Feather scoring}

The results of feather scoring displayed that the average feather score for each individual part of the body and an overall average score for hens were not significantly different among different tiers $(P>$ 0.05). Interestingly, the feather score of the neck was significantly lower than that of other body parts $(P<$ 0.05). Furthermore, the average feather score for each individual part of the body and an overall average score for roosters did not change substantially $(P>0.05)$. 
Table 5

feather score of body parts of layer breeders among different tiers in the mating cage

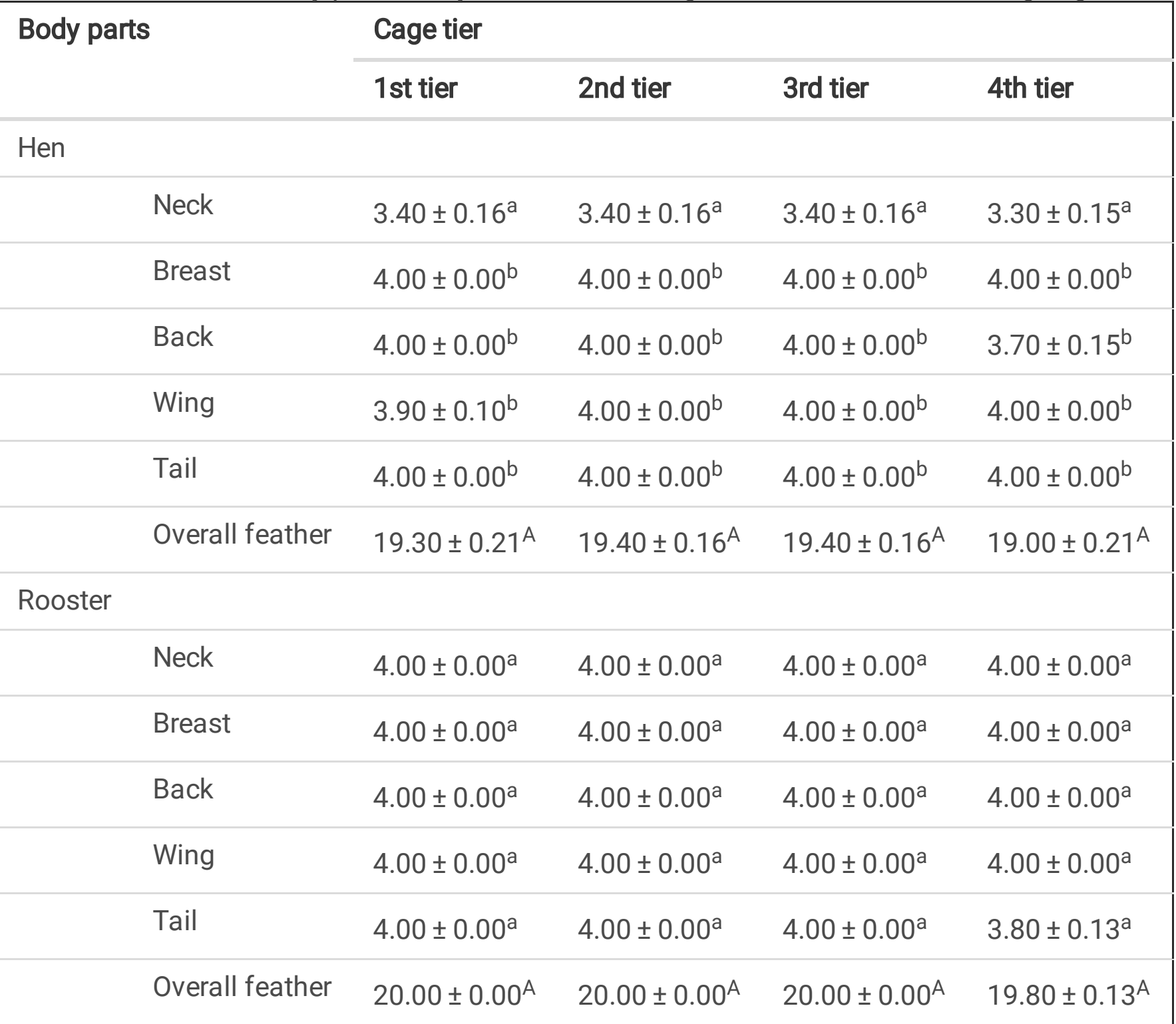

Means followed by the same letter are not significantly different $(P>0.05)$. Lowercase letters are for columns and capital letters are for rows.

\section{Discussion}

Laying performances and mortality are important productive performances and have a substantial economic implications for poultry industry. A wealth of evidence has reported their changes in different cases (Zhao et al. 2019; Geng et al. 2020; Zhao et al. 2019; Han et al. 2017). However, few researchers attempted to list systematically this information at different tiers. In the present work, we examined mortality and laying performances at each cage tier. Gratifyingly, the results displayed that no dead bird was found during the experiment. This results strongly hinted that the experimental birds were healthy, which is an indispensable prerequisite for smooth implementation of the experiment. The highest laying rate was recorded at $2 \mathrm{nd}$ tier, followed by 4 th tier and $3 \mathrm{rd}$ tier, and the lowest at $1 \mathrm{st}$ tier. These results were in conflict with the findings of Sekeroglu et al. (2014). Conversely, our findings were mostly parallel to 
those of Yildiz et al. (2006), who found that cage tier had significant effect on egg production. Admittedly, light is a fundamentally important factor affecting age at first egg and laying rate of the flock (Hassan et al. 2013). Although light intensity was not measured in the present experiment, the fact is that the light bulb is closest to the 2 nd tier of battery cages, followed by the 3rd and 4th tiers, and the farthest 1 st tier. Moreover, the actual amount of light illuminating 1st tier might be blocked by manure belt of the upper tiers. These are probably the reasons for difference in laying rate. Wherefore, it is necessary to optimize the light fixtures and layout to minimize variations in light intensity among different tiers. No differences in percentage of defective eggs were observed in the studied groups. Conceivably, this phenomenon might partially attribute to consistency in shell breaking strength. Hatching experiments manifested that there were no significant differences among different tiers in terms of fertility, rate of water loss, male-tofemale ratio, hatchability of setting eggs, percentage of healthy chicks and average pullet hatching weight, which suggests the possibility that cage tier did not affect hatching performances of laying hens.

Egg quality contains a number of characteristics, related to the yolk, the albumen and the shell, be divided into internal and external egg quality (Roberts 2004; Duman et al. 2016). Egg quality is not only an important indicator for nutritional value, but it is also important for consumer appeal, egg price, hatchability performance, etc (Li et al. 2018; Duru et al. 2017; Blanco et al. 2014; Hrnčár et al. 2014; Zaheer 2015; Adedeji et al. 2015). Although it is well documented, little information is available at different tiers in the mating cage. Therefore, it is interesting to explore the effect of cage tier on egg quality characteristics. Inexplicably, yolk color was significantly lower at 2 nd tier than at other tiers. It was in contradiction with the previous findings of Karaman et al. (2013) and Yildiz et al. (2006), which demonstrated that effect of cage tier on yolk color were found to be insignificant. Since yolk color is mainly affect by exogenous pigment (Roberts 2010). Regrettably, the mount of pigment in the feed was not measured in this study. Our study may not be able to completely explain the current differences and need further exploration. No significant differences in egg weight were recognized at different tiers. The result agreed with Yildiz et al. (2006) and Sekeroglu et al. (2014) but contradicted the conclusions that heavier eggs were produced at the bottom tier (Roy et al. 2014; Bish et al. 1985; Appleby and Michael 1984). Analogously, there were no statistically significant differences in shell color, shell weight, and shell breaking strength (Şekeroğlu et al. 2014). Similar to previous findings, the results showed no substantial change in egg shape index in all groups (Yildiz et al. 2006). Furthermore, little variation was found in Haugh unit. Given that Haugh unit commonly used as an indicator of egg freshness (Dong et al. 2018; Sun et al. 2015; Chung and Lee, 2014). The results indicated that eggs laid at different tiers can be collected together for the same freshness condition. There was no remarkable difference in albumen height. This is predictable because Haugh unit is calculated based on albumen height and positively correlated with it (Yildiz et al. 2006; Roberts 2004; Eisen et al. 1962). Additionally, there were no significant differences in yolk weight because of the similar egg weight, shell weight and albumen height at different tiers. In brief, cage tier had a significant effect on yolk color, but had no effect on other egg quality characteristics.

Blood is a bodily fluid in animals that is composed of blood cells and plasma. Blood has important functions in material transportation, temperature regulation, host immune and acid-base balance. Blood 
biochemical profiling is a useful tool in monitoring the health status, disease diagnosis and other physiological functions. In our study, serum biochemical indicators were determined on each subject individually. Results displayed that concentrations of serum CK showed no substantial differences among different tiers. Acknowledgedly, CK is the key enzyme of ATP metabolism in animal cells and plays a key role in energy metabolism (Li et al. 2020). Relatively stable of CK in the blood of hens indicated their stable energy response to cage tier, which is very important to maintain life. Total antioxidant capacity (TAC), a very common and important parameter concerning physical health, considers the cumulative effect of all antioxidants present in blood and body fluids (Suresh et al. 2009). Malondialdehyde (MDA) is a well-established marker of oxidative stress, and SOD and GPx are considered as key antioxidant enzymes (Li et al. 2017; Cui et al. 2018; Kumar et al. 2007). Their concentrations, to some extent, appears to reflect the oxidative stress status. In this research, no striking differences were found in levels of serum T-AOC, MDA, SOD and GPx among different tiers. Consequently, we boldly speculate that the level of oxidative stress in the body were not affected by cage tier. This deduction was largely in agreement with the findings of previous studies (Onbaşılar and Aksoy 2005). Quite coincidentally, a similar phenomenon was observed for roosters, indicating that there were no gender differences in oxidative stress caused by cage tier. Collectively, our overall results demonstrated that change in cage tier causes negligible effects on the oxidative stress.

Avian influenza and newcastle disease are two of the most devastating diseases of poultry and impose a severe economic burden on the poultry industry throughout the world. It is of fundamental importance to monitor the antibody titers of the flock. Serum antibody titer, the most common immune test that measures the presence and amount of antibodies in blood, was carried out in the work. As expected, the antibody titers of all samples did not change substantially among different tiers. These findings largely agreed with the results of OnbaYVlar and Aksoy (2005). The results basically indicates that cage tier had no significant effect on antibody response. Further analysis found that each antibody titer in the blood of birds was higher than 6 , which reached the level of immune protection and played an important role in protecting the body against infection.

Feather condition has been reported to be associated with laying hen performance and welfare (Labrash and Scheideler 2005; Cook et al. 2006; Saraiva et al. 2016). Currently, the most widely used method for assessment of feather condition is feather scoring. In the present work, the average feather score for each individual part of the body and an overall average score for birds were not significantly different among different tiers. Our results were consistent with previous results (Onbaşılar and Aksoy 2005). On the one hand, as birds selected in this study were relatively young, they grow vigorously and quickly renew their feathers; on the other hand, cumulative pecking and trampling effects on feather may be too short to cause a severe feather loss. These are probably the reasons why feather score for birds were quite high and showed no substantial differences among different tiers. Interestingly, the feather score of the neck was significantly lower than that of other body parts, which makes distinct contacts with the cage door while eating can explain the neck feather conditions. It is necessary to optimize the cage door structure of natural mating system to minimize adverse impacts on the flock. 
In conclusion, we investigated the effect of cage tier on laying performances,blood biochemical indicators, feather condition and antibody titers of layer breeders among different tiers in mating cages during the peak laying period. Although there were no significant differences in terms of mortality, hatchability performances, blood biochemical indicators, feather condition and antibody titers, we found remarkable differences in laying rate and yolk color among different tiers. As laying rate is one of the most important economic traits in the poultry industry, we confidently conclude that cage tier may be a contributing factor for layer performances. These findings will be helpful for application of natural mating system in layer industry.

\section{Declarations}

\section{Acknowledgments}

This study was jointly supported by China Agriculture Research System of MOF and MARA (CARS-40) and the national natural science foundation of china (31601932). We also want to express our sincere appreciation to the staffs at jiangxi huayu poultry breeding co., Itd for their assistance and contributions (yichun, jiangxi, China).

\section{Statement of Animal Rights}

All birds were managed according to the guidelines in the Hy-Line parent stock Management Guide. Animal care protocols and experimental procedures in this study were approved by the Animal Care and Use Committee of the Anhui Academy of Agricultural Sciences and performed in accordance with the Regulations for the Administration of Affairs Concerning Experimental Animals (State Council, China, 2017, Revision).

\section{Authors'contributions}

Yan LI performed the animal trail, finished the statistical analysis and drafted the manuscript. Kai ZHAN conceived and designed the entire experimental plan. Junying LI, Wei LIU, Ruiyu MA, Yi WAN and Renrong QI participated in egg quality analysis, determination of blood biochemical parameters and antibody titer, and scoring of the plumage. Haijun cui and xin zhang provided essential experimental animals and site. All authors read and approved the final version of the manuscript.

\section{Conflict of interest statement}

Authors have declared no conflict of interest

\section{Data availability Statement}

All data included in this study are available upon request by contact with the corresponding author.

\section{References}


Adedeji, T. A., Amao, S. R., Popoola, A. D. and Ogundipe, R. I. (2015). Fertility, hatchability and eggs quality traits of Nigerian locally adapted chickens in the derived savanna environment of Nigeria. Journal of Biology, Agriculture and Healthcare, 5(17), 36-42.

Appleby, M. C. (1984). Factors affecting floor laying by domestic hens: a review. World's Poultry Science Journal, 40(3), 241-249..

Bilcik, B., I. Estevez and E. Russek-Cohen, Reproductive success of broiler breeders in natural mating systems: the effect of male-male competition, sperm quality, and morphological characteristics. Poultry Science, 2005. 84(9): 1453-62.

Bish, C. L., Beane, W. L., Ruszler, P. L. and Cherry, J. A. (1985). Body weight influence on egg production. Poultry Science, 64(12), 2259-2262..

Blanco, A. E. , Icken, W. , Ould-Ali, D. , Cavero, D. and Schmutz, M. . (2014). Genetic parameters of egg quality traits on different pedigree layers with special focus on dynamic stiffness. Poultry Science, 2014. 93(10): 2457-63.

Brillard, J., Natural mating in broiler breeders: present and future concerns. World's Poultry Science Journal, 2004. 60(4): 439-445.

C Hrnčár, E Hanusová, Hanus, A. and Bujko, J. . Effect of genotype on egg quality characteristics of Japanese quail (Coturnix japonica). slovak journal of animal science, 2014.

Chung, S. H. and Lee, K. W. (2014). Effect of hen age, storage duration and temperature on egg quality in laying hens. International Journal of Poultry Science, 13(11), 634.

Cook N J , Smykot A B , Holm D E, et al. Assessing Feather Cover of Laying Hens by Infrared Thermography[J]. Journal of Applied Poultry Research, 2006, 15(2):274-279.

Cui, X., Gong, J., Han, H., He, L., Teng, Y., Tetley, T. and Zhang, J. J. (2018). Relationship between free and total malondialdehyde, a well-established marker of oxidative stress, in various types of human biospecimens. Journal of thoracic disease, 10(5), 3088.

Dong, X., Li, Z., Shen, Z. and Tang, X. (2018). Nondestructive egg freshness assessment from the equatorial and blunt region based on visible near infrared spectroscopy. Spectroscopy Letters, 51(10), 540-546.

Duman, M. , Ekerolu, A. , Yldrm, A. , Elerolu, H. and Camci, O. . (2016). Relation between egg shape index and egg quality characteristics. Archiv fur Geflugelkunde, 2016. 80: 1-9.

Duru, M. , Duru, A. A. , Karadas, K. , Eyduran, E. and Tariq, M. M. . (2017). Effect of Carrot (Daucus carota) Leaf Powder on External and Internal Egg Characteristics of Hy-Line White Laying Hens. Pakistan journal of zoology, 2017. 49(1). 
Eisen, E. J., Bohren, B. B. and McKean, H. E. (1962). The Haugh unit as a measure of egg albumen quality. Poultry Science, 41(5), 1461-1468.

Geng, A. L. , Liu, H. G. , Zhang, Y. , Zhang, J. and Yan, Z. X.. Effects of indoor stocking density on performance, egg quality, and welfare status of a native chicken during 22 to 38 weeks. Poultry science, 2020. 99(1): 163-171.

Grover, R. M., Anderson, D. L., Damon Jr, R. A. and Ruggles, L. H. (1972). The effects of bird density, dietary energy, light intensity, and cage level on the reproductive performance of heavy type chickens in wire cages. Poultry Science, 51(2), 565-575.

Han, X. J., Qin, P., Li, W. X., Ma, Q. G., Ji, C., Zhang, J. Y. and Zhao, L. H. Effect of sodium selenite and selenium yeast on performance, egg quality, antioxidant capacity, and selenium deposition of laying hens. Poultry Science, 2017. 96(11): 3973-3980.

Hassan, M. R., Sultana, S., Choe, H. S. and Ryu, K. S. Effect of monochromatic and combined light colour on performance, blood parameters, ovarian morphology and reproductive hormones in laying hens. Italian Journal of Animal Science, 2013. 12(3): 359-364.

Hurnik, J. F., Piggins, D. J., Reinhart, B. S. and Summers, J. D. The effect of visual pattern complexity of feeders on food consumption of laying hens. British Poultry Science, 1974. 15(1): 97-105.

Jackson, M.E. and Waldroup P.W., Research Note: Effect of Cage Level (Tier) on the Performance of White Leghorn Chickens - ScienceDirect. Poultry Science, 1987. 66(5): 907-909.

Karaman, S., Sekeroglu, A. and Duman, M.. Physical Characteristics and Performance of Laying Hens Caged in Different Tiers and Environmental Parameters of Each Tier. Transactions of the Asabe, 2013. 56(1): 321-328.

Kumar, A., Pant, P., Basu, S., Rao, G. R. K. and Khanna, H. D. (2007). Oxidative stress in neonatal hyperbilirubinemia. Journal of tropical pediatrics, 53(1), 69-71.

Labrash L F , Scheideler S E . Farm Feather Condition Score Survey of Commercial Laying Hens[J]. The Journal of Applied Poultry Research, 2005, 14(4):740-744.

Li, C., Wang, W., Lee, J., Zeng, L., Yang, Y., Yin, S. J. and Qian, G. Y. (2020). Comparative studies of the expression of creatine kinase isoforms under immune stress in Pelodiscus sinensis. International journal of biological macromolecules, 162, 11-23.

Li, S. W., Sun, X., He, Y., Guo, Y., Zhao, H. J., Hou, Z. J. and Xing, M. W. (2017). Assessment of arsenic trioxide in the heart of Gallus gallus: alterations of oxidative damage parameters, inflammatory cytokines, and cardiac enzymes. Environmental Science and Pollution Research, 24(6), 5781-5790. 
Li, Y., Zhan, K., Li, J., Liu, W., Ma, R., Liu, S. and Hu, Y. (2018). Comparison of natural mating and artificial insemination on laying performance, egg quality and welfare of fast feathering huainan partridge chickens. Pakistan Journal of Zoology, 50(3), 1131-1135.

Onbaşlar, E. E. and Aksoy, F. T. (2005). Stress parameters and immune response of layers under different cage floor and density conditions. Livestock Production Science, 95(3), 255-263.

Roberts, J. R. (2004). Factors affecting egg internal quality and egg shell quality in laying hens. The Journal of Poultry Science, 41(3), 161-177.

Roy, B., Ali, M. A., Sarkar, P. K., Sarker, P. K., Kawsar, M. H. and Shah, M. (2014). Laying behaviour of egg and meat type chicken as influenced by nest tier. Wayamba Journal Of Animal Science, 6, 839-844.

Saraiva S , Saraiva C , Stilwell G . Feather conditions and clinical scores as indicators of broilers welfare at the slaughterhouse[J]. Research in Veterinary Science, 2016:75-79.

Sefton E. A., The Interactions of Cage Size, Cage Level, Social Density, Fearfulness and Production of Single Comb White Leghorns. Poultry Science, 1976. 55(5): 1922-1926.

Şekeroğlu, A, Duman, M. , Y Tahtalı, A Yıldırım and H Eleroğlu.Effect of cage tier and age on performance, egg quality and stress parameters of laying hens. South African Journal of Animal Science, 2014. 44(3).

Sun, L., Yuan, L. M., Cai, J. R., Lin, H. and Zhao, J. W. (2015). Egg freshness on-line estimation using machine vision and dynamic weighing. Food Analytical Methods, 8(4), 922-928.

Suresh, D. R., Annam, V., Pratibha, K. and Prasad, B. M. (2009). Total antioxidant capacity-a novel early bio-chemical marker of oxidative stress in HIV infected individuals. Journal of biomedical science, 16(1), $1-4$.

Tauson, R. Avoiding Excessive Growth of Claws in Caged Laying Hens. Acta Agriculturae Scandinavica, 1986. 36(1): 95-105.

Yildiz, A., Lacin, E., Hayirli, A. and Macit, M, Effects of cage location and tier level with respect to light intensity in semiconfined housing on egg production and quality during the late laying period. Journal of applied poultry research, 2006. 15(3): 355-361.

Zaheer, K., An Updated Review on Chicken Eggs: Production, Consumption, Management Aspects and Nutritional Benefits to Human Health. Food and Nutrition Sciences, 2015. 6(13): 1208-1220.

Zhao, S., Zhang, K., Ding, X., Celi, P., Yan, L., Bai, S. and Wang, J.The impact of dietary supplementation of different feed additives on performances of broiler breeders characterized by different egg-laying rate. Poultry science, 2019. 98(11): 6091-6099. 
Zhao, Y., Li, X., Sun, S., Chen, L., Jin, J., Liu, S. and Lu, L. Protective role of dryland rearing on netting floors against mortality through gut microbiota-associated immune performance in Shaoxing ducks. Poultry science, 2019. 98(10): 4530-4538. 